\title{
"EFICAZ PLAN PARA RESOLVER LA DESNUTRICION INFANTIL Y DE PASO LOS PROBLEMAS FISCALES": UNA SATIRA A LA ALIENACION COLECTIVA
}

María Elia Rodríguez Herrera

\begin{abstract}
A semiotic analysis is made of a text by the playwright Alberto Cañas as a way to reading the supersign which has been chosen and which will permit us to understand, not only its internal structural organization, but also the underlying social relations which it displays and which are the consequence and reflection of its socioeconomic context.
\end{abstract}

\section{ASPECTOS INTRODUCTORIOS}

Alberto Cañas, ese polifacético humanista costarricense del Siglo XX, cuyo aporte es indiscutible en el desarrollo de nuestra cultura, ha motivado nuestro interés para estudiar una de sus obras dramáticas menos conocidas: Eficaz plan para resolver la desnutrición infantil $y$ de paso los problemas fiscales (1).

Esta obra es una sátira social enmarcada en el teatro del absurdo, del cual toma algunos recursos para expresar la contradictoria existencia del hombre del siglo XX.

El texto dramático está basado en una obra del autor de Los viajes de Gulliver, el inglés Jonathan Swift, quien en 1729 escribió $A$ modest proposal for preventing the children of Poor People from being a Burthen to their Parents, or the Country and for making them Beneficial to the Publick", obra que satiriza con tonos caústicos y paradójicos la indignación del autor por la pobreza de Irlanda en esa época.

Alberto Cañas se sirve de la idea fundamen. tal de Swift (comerse los niños de los pobres para terminar con éstos) y la desarrolla bajo dos diferentes perspectivas, ambas aderezadas por un firıo y penetrante humor negro: la obra dramática objeto de este análisis, la cual adapta el tema al drama y va más allá de su fuente originaria, y un relato breve: La exterminación de los pobres (2), en el que plantea el problema de la esterilización como medio de acabar con los pobres.
El presente es un intento de análisis semiótico de la obra antes citada, que ha sido puesta en escena una vez en 1976 por el grupo Taller del Instituto Tecnológico, bajo la dirección de Olga Marta Barrantes.

Además de establecer vínculos significativos entre la obra estudiada y la de Swift, pretendemos realizar una lectura del supersigno que nos permita captar, no sólo su organización estructural interna, sino también las relaciones sociales subyacentes en ella y que son producto y reflejo de su contexto socioeconómico.

\section{SEGMENTACION CUANTITATIVA DEL SU. PERSIGNO}

La obra transcurre en un sólo acto, constituido por 106 parlamentos y formalmente no tiene escenas, aunque sí de hecho. Hay dos fragmentaciones internas en el texto, señaladas por idénticos elementos:

2.1 El retiro de escena de un personaje y el ingreso de otro (u otros) tras una pausa evidente.

2.2 El cambio de enfoque en la temática de la conversación.

2.3 La reiteración de la misma frase de cortesía y saludo en boca de varios personajes.

2.4 Las indicaciones, acerca de los anteriores cambios, hechas en lenguaje acotacional.

2.1 La primera parte concluye en el parlamento número cuarenta, al retirarse de escena la Señora Elegante y hacer su ingreso la Secretaria, con 
quien se efectúa un cambio de tono, relación personal y temática, los cuales serán analizados más adelante.

La segunda parte concluye en el parlamento número noventa y siete, al retirarse de escena la Secretaria e ingresar seis nuevos personajes, quienes también varían su tono y el contenido de sus intervenciones.

La tercera y última parte concluye con el telón final, en el parlamento número ciento seis.

2.2 Las tres partes evidencian, asimismo, un cambio en el enfoque de la conversación, la cual gira siempre en torno al quehacer del Instituto $\mathrm{Na}$ cional de Nutrición y Engorde, pero pone de relieve la perspectiva que sobre él y sus alcances sociales tienen representantes de varios sectores.

2.3 El otro elemento del acto único es la reiteración del "Buenos Días" en boca de diferentes personajes y con tono también diferente, según sea el nivel social de quien lo pronuncia. El saludo permite iniciar o concluir la relación que se establece entre diferentes personajes:

\section{Señora Elegante-Funcionario}

Funcionario-Secretaria

Damas Elegantísimas-Vendedores

En la primera parte, en labios de la Señora Elegante y del Funcionario, es la fórmula de despedida cortante y seca con que concluyen los parlamentos habidos entre ellos.

Al inicio de la segunda parte, más larga y densa, el "Buenos Días" actúa, a su vez, como saludo cursi, al ser pronunciado por la Secretaria y, otra vez, por el Funcionario.

En la tercera parte, es el Vendedor primero quien pronuncia el "Buenos Días" como saludo cortés y respetuoso hacia la Primera Dama Elegantísima.

2.4 El lenguaje de las acotaciones constituye el otro elemento que reafirma las partes en que se ha segmentado el acto único que constituye la obra.

El final de la primera parte lo enmarcan tres elementos: el cortante "Buenos Días" ya citado, la salida de la Señora Elegante y un fallido portazo.

Todos estos elementos están indicados en el paréntesis que sigue al parlamento número cuarenta. Curiosamente se repiten, casi idénticos, al final del parlamento noventa y siete, con el que se inicia la tercera parte. El portazo aquí es ya un hecho, pero consumado por otro personaje femenino: la Secretaria, quien también había ingresado a escena con un "Buenos Días". (Cfr. págs. 72, 78, 79 del texto analizado).
La tercera parte vuelve a repetir la estructura ya citada: salida de un personaje (la Secretaria), un portazo y entrada a escena de alguien; esta vez, seis nuevos personajes.

El lenguaje acotacional define en los tres casos, de manera precisa y clara, el tono y la gestualidad de los personajes, que la puesta en escena hará evidente en todos, para marcar las diferencias significativas que tienen los mismos hechos o palabras en personajes diferentes y las cuales apuntan a diferencias sociales como luego se verá.

El siguiente cuadro es un resumen de la segmentación cuantitativa de la obra.

CUADRO No. 1

\begin{tabular}{lccc}
\hline Partes & I & II & III \\
\hline Parlamentos & 40 & 57 & 9 \\
Personajes & 2 & 2 & 7 \\
$\begin{array}{l}\text { Personajes como } \\
\text { realidades verbales }\end{array}$ & 5 & 2 & $\begin{array}{c}2 \\
\text { y otros } \\
\text { sin enumerar }\end{array}$ \\
\hline
\end{tabular}

Con base en los datos del cuadro No. 1 se pueden hacer las siguientes observaciones:

La primera parte tiene una duración intermedia por el número de parlamentos (40). En ella participan 2 personajes y se hace referencia a cinco que no aparecen en escena, pero que, según se verá, aclaran la conformación social del grupo que se muestra. La segunda parte es la más extensa de la obra (57 parlamentos) y descansa en sólo dos personajes, uno de los cuales (Ojeda) había aparecido ya en la primera parte. Hay alusión a otros dos sujetos: uno, el universitario, del mundo dramático creado por Alberto Cañas y el otro, referencial, explicará, junto con el paréntesis que sigue al título de la obra, la base anecdótica y el autor que sirvieron de fuente inspiradora al dramaturgo en esta creación ("un escritor y clérigo inglés", p. 76).

La tercera parte es la más breve; consta sólo de 9 parlamentos en boca de 7 personajes. Aumenta pues, notablemente, el número de personajes en escena y también los que constituyen realidades verbales. Ambos grupos, se verá, contribuyen a enfatizar más aún la conformación social esbozada en la primera parte.

El cuadro No. 2 resume los personajes participantes en la obra con sus parlamentos y lugar de intervención. 
CUADRO NO. 2

\begin{tabular}{|c|c|c|}
\hline Personaje & Parte & Parlamento \\
\hline Funcionario Ojeda & $1,11,111$ & $51(20,28,2)$ \\
\hline Señora Elegante & 1 & 20 \\
\hline Secretaria & II & 29 \\
\hline Vendedor I & 111 & 1 \\
\hline Vendedor II & III & 2 \\
\hline $\begin{array}{l}\text { Miguelillo (Vendedor I } \\
\text { III) }\end{array}$ & III & 1 \\
\hline $\begin{array}{l}\text { Doña Austelia (Primera } \\
\text { Dama Elegantísima) }\end{array}$ & III & 1 \\
\hline $\begin{array}{l}\text { Doña Brunilda (Segunda } \\
\text { Dama Elegantísima) }\end{array}$ & III & 1 \\
\hline $\begin{array}{l}\text { Tercera Dama Ele- } \\
\text { gantísima }\end{array}$ & 111 & 1 \\
\hline
\end{tabular}

El análisis cualitativo que se deriva del cuadro será desarrollado más adelante, en los niveles sintáctico y semántico.

\section{SEGMENTACION CUALITATIVA DEL SU. PERSIGNO}

El nivel sintáctico de la obra presenta una organización clara, definida y equilibrada en cuanto a los signos que lo conforman.

\subsection{Los signos-personaje}

Citados en el cuadro Número dos, los signos-personaje ofrecen una gradación en orden de importancia y significación en la obra.

El funcionario Ojeda, la Señora Elegante y la Secretaria son los personajes básicos. Es por ello que presentan características particulares, que los individualizan como los prototipos sociales cuyas denominaciones representan. Ojeda es, en verdad, el funcionario burócrata encargado de las relaciones públicas en una oficina estatal: el Instituto de Nutrición y Engorde.

Es un hombre joven de algo más de 30 años, vestido impecablemente de gabacha blanca, que, según dice, le da aspecto de serio, trabajador, estudioso y aseado. Maneja sus códigos lingü ístico, gestual y proxémico de acuerdo con las calidades de sus interlocutoras.

Constituye uno de los soportes de la obra pues aparece en las tres partes de la misma, interactuan- do con diferentes personajes, y desenvolviéndose según un rol evidentemente aprendido para cada ocasión.

En la primera parte es el típico empleado que, consciente del relativo poder que le da su puesto, explota esa aparente superioridad frente a la dama que, por su condición socioeconómica está por encima de él, pero quien debe, finalmente, acatar las reglas impuestas con deleite por el oscuro funcionario. Este oscila entre la imposición y el sometimiento, la superioridad laboral y la inferioridad social.

En la segunda parte, Ojeda mantiene una doble rełación con su Secretaria.

Por un lado, es una relación de superioridad laboral, de imposición; por el otro, de sometimiento. El poder que le da su cargo le permite colocarse en un nivel de mando y de autoridad sobre la muchacha. La condición social, en cambio, to hace ubicarse en una línea casi paralela a la empleada, quien también vive de un salario, aunque menor, y del favor de sus superiores, y quien lo somete a sus propias condiciones para una eventual relación amorosa.

En la tercera parte Ojeda se ubica nuevamente en una doble línea significativa: de superioridad laboral e imposición frente a los vendedores y al ordenanza, con los cuales, empero, manifiesta una semejanza social; de inferioridad laboral y social, o sometimiento, frente al Ministro de Ingresos Fiscales y frente a las damas elegantísimas que llegan a adquirir sus productos. Ojeda, finalmente, hace honor a su nombre, pues se constituye en un nuevo sátrapa, al igual que los antiguos "ojos $y$ oídos" del Emperador persa.

\section{La Señora Elegante}

Es también un prototipo social. Por eso no tiene nombre propio, se la define y conoce por su doble condición: "señora" y "elegante".

Es una mujer atractiva, de "treinta y pico de años", educada según su condición de clase, con fortuna propia y marido de adorno, vestida a la última moda y recargada de joyas, como corresponde a su nivel; exigente, teatral y convencida del poder infalible del dinero.

Su participación en la obra ayuda a confirmar la doble línea de imposición y sometimiento en que se mueven los personajes, así como la alienación que los envuelve. 


\section{La Secretaria}

Es una muchacha alta, joven, bonita, provocativa $y$ eficiente en su trabajo. Manifiesta los ideales comunes a su edad y condición: casarse y tener hijos. Asimismo introduce un elemento disfórico en la conformación de los valores manifestados por los otros personajes: el remordimiento y la duda sobre lo que se hace en la Institución. Es la voz de la conciencia individual frente a la alienación colectiva. Sin embargo su posición es débil y no logra imponerse; su fuerza sólo se manifiesta en el portazo con que deja la escena para no volver.

Sus parlamentos y actitudes, empero, ofrecen la visión caricaturizada pero realista que la obra transmite al espectador acerca de las consecuencias de la burocracia y sus efectos.

Los demás personajes que intervienen pueden ser caracterizados en dos bloques: las amas y los servidores.

El bloque de las amas lo conforman las tres Damas Elegantísimas, identificadas por su número (Primera, Segunda y Tercera), por sus cursis nombres acompañados del título "doña" (Doña Austelia, Doña Brunilda) y por el séquito de servidores mudos que las acompañan. El superlativo que las denomina ("Elegantísimas") da sus calidades personales; la especialidad solicitada en el Instituto define el status de cada una.

El bloque de los servidores también está formado por tres, identificados, de igual forma que las amas, por su número (Primero, Segundo, Tercero). El equilibrio estructural de este bloque con respecto al anterior, lo da no sólo la numeración idéntica, sino también el nombre del Vendedor Tercero, Miguelito, que ofrece un contraste socioeconómico marcado por el diminutivo frente al solemne "Doña" que acompaña a los nombres de las damas.

\subsection{Realidades objetivas físicas}

La obra es muy explícita en cuanto a las realidades objetivas físicas, que se destacan por el empleo de diferentes signos.

\section{Signos visuales}

Son numerosos, como corresponde al espectáculo dramático.

La oficina del Encargado de Relaciones Públicas del Instituto Nacional de Nutrición y Engorde está ubicada en el primer piso del edificio recién construido. Tiene dos puertas, una al exterior y otra al interior. En ella está el escritorio del Funcionario
Ojeda, con varios teléfonos, sillas, un reloj de pared y una gran división corrediza que la separa del Departamento de Ventas.

En éste hay un mostrador en el que se guarda la "mercadería" y detrás de él aparecen los vendedores con cuchillos en las manos. El lenguaje acotacional insiste notablemente en la adjetivación connotativa que acompaña a los signos visuales: el blanco está presente en paredes, gabachas, delantales, mostrador. Lo moderno y la abundancia se destacan en los muebles, la oficina y el edificio de varios pisos. También en la elegancia de las damas, sus trajes y sus joyas, que son signos explícitos de su condición social.

La minifalda de la Secretaria es otro signo visual importante, como recurso definidor de clase y tipo social.

\section{Signos espacio-temporales}

Ubican la acción, no sólo en el espacio cerrado de la oficina, sino en un día jueves por la mañana, entre las nueve y treinta y las diez horas.

\section{Indicadores auditivos}

Hay algunos. Por ejemplo los portazos, las campanadas del reloj y el timbre con que se llama al ordenanza.

\section{Signos prosódicos}

Enmarcan las diferencias en el tono de los parlamentos ("sigiloso", "melodramático", "terminante", etc.)

\section{Signos kinésicos y proxémicos}

Refuerzan las relaciones y la condición sociales de los personajes, puesto que insisten en patrones de conducta que son típicos de cada uno: las damas y sus criados, el burócrata y sus subal ternos y todos estos, asalariados del estado.

\subsection{Realidades verbales}

Son varias. En la primera parte aparecen el señor Fergusson, el esposo de la Señora Elegante, el Gerente, el Jefe de Personal, los niños desnutridos, y la referencia de la Señora Elegante a la ida al aeropuerto y a la fiesta que deberá ofrecer en la noche.

En la segunda parte son realidades verbales el empleado universitario, la misión de las Naciones Unidas, un escritor y clérigo inglés (J. Swift) y el informe sobre las actividades del Instituto. 
En la tercera parte constituye un "fuera de escena" el encargo, ya listo, que llega a recoger la Tercera Dama Elegantísima.

\subsection{El Complejo manifiesto y sus iteraciones}

La obra consta de un solo complejo, el de la alienación colectiva, A, subdividido en tres iteraciones:

$A_{1} \quad$ La iteración de la superioridad social.

$\mathrm{A}_{2}$ La iteración de la superioridad laboral.

$A_{3}$ La iteración de la concientización fallida.

\section{$A_{1}$ Iteración de la superioridad social}

Es la más importante de la obra y por eso se considera la englobante.

Todos los signos-objeto que la conforman evidencian las diferencias sociales a que apunta su contenido semántico:

"traje mañanero espectacular" (p. 68) / "delantales muy blancos" (p. 79).

"joyas que cuelgan de su cuello, sus brazos y sus dedos" (p. 68).

/"enormes cuchillos en las manos" (p. 79).

Asimismo, las fórmulas de cortesía empleadas en el trato interpersonal manifiestan oposición: 69)

"estimabilísima señora" (p. 69) /“joven" (p.

"dama importantísima" (p. 69) /"hombre de tendencias minoritarias" (p. 72)

"Doña Brunilda" (p. 79) / "Miguelito" (p. 79)

También comportan diferencias sociales las actividades que realizan los personajes, contenidos en el cuadro No.3.

CUADRO No. 3

$=$

Personajes Actividad

Señora Elegante

Ir al aeropuerto

recoger el pedido en el Instituto

Dar una fiesta en la noche

Funcionario

recibir a las clientes atender al público

Damas Elegantísimas conversar y saludar a otras damas

recoger el pedido

recibir invitados en casa

Vendedores

atender a Damas alistar pedidos
La relación social que se establece en esta iteración es una relación económica basada en el dinero, la posición y la influencia, los tres criterios que según Max Weber rigen la estratificación social (3).

En los parlamentos 28-34 se alude a los dos primeros (dinero y posición) en boca, ya de Ojeda, ya de la Señora Elegante. Ejemplos:

"-Funcionario: .. ya que nuestra clientela, como usted lo sabe, está restringida, por ley a los elementos más destacados y económicamente más poderosos de nuestra sociedad. A los ricos, por decirlo así" (p. 71).

Hay en las palabras del Funcionario una ridiculización y sátira de los medios de acumulación de capital y a la complicidad y silencio estatal al respecto:

- "Y también a los que han llegado a lo mismo por la vía del matrimonio, de la lotería, de la herencia, del contrabando, del peculado, de la estafa, del soborno, de la trata de blancas, del tráfico de drogas y aún del robo con escalamento. Aquí no se hacen preguntas, señora. (p. 70).

-... "Le repito que aquí no se hacen preguntas. Bueno, ni aquí ni en el resto del territorio nacional. El que acredite una cuenta bancaria de determinado volumen queda, por disposición legal, incorporado de pleno derecho a la lista de nuestros clientes y favorecedores" (p. 72).

El poder político también aparece en esta iteración. En la persona de la Señora Elegante se presenta cuando pretende coaccionar a los funcionarios que estén a su alcance para ser atendida aunque el Instituto esté cerrado.

En las Damas Elegantísimas la influencia se refleja en los privilegios de que son objeto por parte de los vendedores, quienes les reservan los mejores "cortes" o las mejores calidades de "carne".

\section{A2 Iteración de la superioridad laboral}

Plantea las relaciones de poder que otorga la burocracia estatal. Se establecen diferencias ocasionadas esta vez por la línea de mando establecida:

Ministro/Ojeda

Señor Director/ Secretaria y Vendedores

Los signos-objeto oponen:

"hombre con gabacha" (p. 73) / mujer con minifalda (p. 74).

La gabacha, según el texto, connota las siguientes cualidades: "fama de serio", "buen trabajador", "estudioso", "aseado" (p. 73). 
La minifalda, en cambio, es vestido "de mujer fácil" (p. 74).

También las fórmulas de cortesía manifiestan la línea de autoridad: "Señor Director"| "muñeca" p. 73).

Hay otras realidades objetivas físicas y verbales que confirman la relación superioridad/inferioridad, desde el punto de vista de la burocracia. Sobre Ojeda hay otros funcionarios de mayor rango a quienes él debe obediencia, respeto y sometimiento.

La línea de autoridad sigue entonces un camino ascendente:

\section{Ojeda $\rightarrow$ Jefe de Personal $\rightarrow$ Señor Gerente}

Las actividades realizadas por cada uno de los empleados también manifiestan la relación en que se fundamenta $\mathrm{A}_{2}$.

El cuadro No.4 resume los personajes participantes y las actividades que realizan.

\section{CUADRO No. 4}

\begin{tabular}{ll}
\hline Personajes & Actividad \\
\hline Ordenanza & $\begin{array}{l}\text { abrir la puerta } \\
\text { introducir a las damas a la } \\
\text { sala }\end{array}$ \\
\hline Vendedor I, II, III & $\begin{array}{l}\text { destazar la carne } \\
\text { preparar los encargos de las } \\
\text { Damas } \\
\text { atender cortésmente a las } \\
\text { Damas }\end{array}$ \\
\hline Secretaria & $\begin{array}{l}\text { entregar el informe al Fun- } \\
\text { cionario } \\
\text { resumir oralmente el conte- } \\
\text { nido del mismo } \\
\text { conversar con el Funciona- } \\
\text { rio } \\
\text { coquetear con el Funciona- } \\
\text { rio } \\
\text { concientizar al Funcionario } \\
\text { del papel que le ha sido im- } \\
\text { puesto. }\end{array}$ \\
\hline \hline Funcionario & $\begin{array}{l}\text { atender al público } \\
\text { enamorar a la Secretaria } \\
\text { cuidar la apariencia del Ins- } \\
\text { tituto } \\
\text { rendir informes a sus supe- } \\
\text { riores }\end{array}$ \\
\hline & $\begin{array}{l}\text { velar por la calidad de la } \\
\text { salir de la ciudad }\end{array}$ \\
\hline & \\
& \\
& \\
\hline &
\end{tabular}

De las funciones enumeradas se desprende una relación interesante entre los empleados. Con excepción de Ordenanza y los Vendedores, cuya labor es muy concreta, práctica y explícita en el lenguaje acotacional, las otras personas realizan actividades que podemos definir como "no cuantificables" y secundarias, es decir, son quehaceres poco definidos, poco claros e intrascendentes: conversar, cuidar la apariencia, velar por la calidad, recibir a alguien, etc.

Nos damos cuenta entonces que las labores pesadas e importantes y concretas están en manos de los funcionarios de menor rango, sobre quienes descansa la mayor responsabilidad. Hay una relación inversamente proporcional a la actividad desarrollada y al estatus burocrático: los bajos empleados tienen sobre sí la verdadera responsabilidad, mientras que los altos solamente ejercen control y presión laborales, puesto que son figuras de poder en la empresa, pero decorativas en sus funciones.

Los altos funcionarios se limitan al parloteo burocrático, que actúa como respuesta del parloteo social de las damas de clase alta, quienes no tienen más actividades que hablar y ordenar, según sus ingresos y deseos. Se completa entonces la pirámide: Ia clase alta no realiza actividades, solo habla y ejerce el control y la superioridad sobre los que están más abajo en la pirámide social.

Hay sin embargo un común elemento entre ellos: la alienación que los mantiene unidos por la misma inconsciencia frente al mundo.

\section{Interacción $A_{3}$ : de la concientización fallida}

La interación $\mathrm{A}_{3}$ es la más breve, sin embargo es fundamental para la significación y estructura de la obra, pues conlleva un proceso inconcluso: la concientización fallida que responde al polo negativo $(\bar{S})$ del invariante semántico, como se verá luego. Hay en ella elementos básicos, por ejemplo el parlamento No. 70 .

"A mí a veces me preocupa, casi me remuerde la conciencia" (p. 78).

El número 95 :

"Si fueras de verdad un ser humano, y si yo fuera un ser humano que es cosa de que no estoy segura, la palabra negociar, no surgiría entre nosotros" (p. 78).

En ambos parlamentos se pone de manifiesto la idea de la concientización. Los personajes dialogan sobre ella, ofrecen sus puntos de vista, descubren la interioridad de sus personas, donde subyacen 
valores del código ético que se transgrede en la obra, y el cual aparece como lo caduco:

"...el egoísmo maternal, vieja figura del sentimentalismo y la moralidad antiguos" (p. 77).

La esencia del hombre, su humanidad, su espiritudalidad, se plasma como un resto, algo de dudosa vigencia.

"...todavía tengo algo de humano" (p. 78).

Esos valores espirituales se oponen a las necesidades prácticas, materialistas, de carácter económico-social.

"... tu obligación es preocuparte porque el Instituto prospere y cumpla con su deber" (p. 78).

"...No. No podemos permitir que no haya niños desnutridos. Tenemos que producirlos..." (p. 76).

La Secretaria, como portadora de $\bar{S}$ (no alienación) es un vehículo débil, que no logra imponerse al Funcionario, ubicado en $\mathrm{S}$ (alienación) por su condición laboral y por el proceso mental de burocratización que esa condición le ha impuesto.

\subsection{El Invariante Semántico}

El supersigno está organizado con base en un doble juego de contrarios, los cuales definen las iteraciones que lo integran. El cuadro número 5 resume en forma gráfica las oposiciones, en el cuadrado semiótico.

\section{CUADRO No. 5}

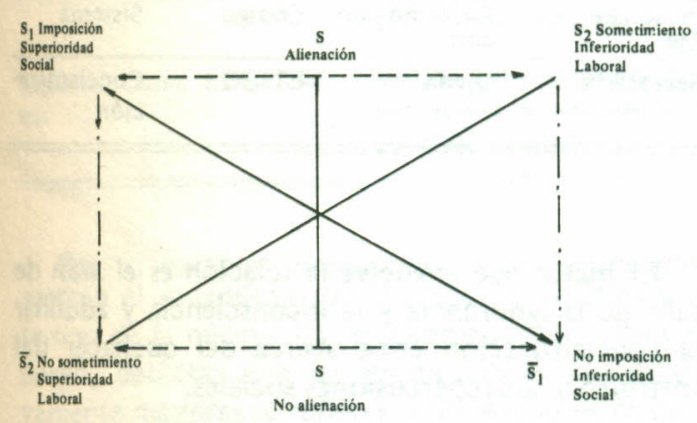

El eje sémico principal $S / \bar{S}$ (alienación/no alienación) define la línea significativa que organiza el microuniverso semántico. El polo positivo es la alienación pues ésta constituye la forma usual de vida, tanto para las damas acomodadas como para los empleados del Instituto Nacional de Nutrición y Engorde.
Las iteraciones $A_{1}$ y $A_{2}$ se inscriben dentro de este polo (S) del eje, puesto que en ambas los personajes y enunciados predicativos y cualificativos, así como el lenguaje acotacional, validan y mantienen ese "ideal" de vida.

La iteración $\mathrm{A}_{3}$ está ubicada en el polo negativo del Eje (S) (no alienación). Sin embargo, se le ha denominado de la concientización fallida al no lograr concretarse plenamente, pues los personajes no logran salir hacia la forma vital y ética sugerida por la Secretaria (parlamento 97) como la verdadera posibilidad de realización personal y social.

Los polos $\mathrm{S} 1, \mathrm{~S} 2$ y $\overline{\mathrm{S}}_{1}, \overline{\mathrm{S}}_{2}$ forman las demás articulaciones dentro de las cudles tiene sentido el contenido semántico de cada una de las iteraciones. $\mathrm{S} 1 / \overline{\mathrm{S}} \mathrm{1}$

$\mathrm{A}_{1}$ inscribe su actividad significativa en la línea

$A_{2}$, al contrario, se ubica fundamentalmente en la línea $\mathrm{S} 2 / \overline{\mathrm{S} 2}$.

A3 se desarrolla en el eje $S / \bar{S}$.

Hay sin embargo, otras relaciones importantes. En la primera interación, $A_{1}$, hay una línea, significativa que puede enunciarse así:

$$
\mathrm{S}=\mathrm{S} 1 \rightarrow \overline{\mathrm{S} 1} ; \overline{\mathrm{S} 2} \rightarrow \mathrm{S} 2
$$

Esta doble relación se explica porque $A_{1}$ es la iteración englobante que se manifiesta como onmipresente en el supersigno.

En $A_{1}$ la Señora Elegante está ubicada en S1 (Superioridad social) mientras que el Funcionario y los vendedores representan el polo S1 (Inferioridad social). A la vez, el Funcionario se ubica en S2 (Superioridad laboral) frente a la Señora (S1) y frente a los vendedores, que están en S2 (Inferioridad laboral). Todos estos personajes, además, están bajo $\mathrm{S}$ (alienación), el código ético que los cobija.

En $A_{2}$ los nexos que se establecen son: $\mathrm{S}=\overline{\mathrm{S} 2} \rightarrow \mathrm{S} 2, \overline{\mathrm{S} 1}$, pues el Funcionario, en relación con la Secretaria y los vendedores participa del polo $\overline{\text { S2 }}$ (Superioridad laboral) la Secretaria y los Vendedores se ubican en S2 y S1 (Inferioridad laboral e Inferioridad social respectivamente). Nuevamente todos participan en esta iteración de $\mathrm{S}$ (alienación).

$\mathrm{En}_{3}$ las relaciones presentes son las que siguen:

$$
\overline{\mathrm{S}}=\mathrm{S} 2, \overline{\mathrm{S} 1} \rightarrow \overline{\mathrm{S} 2}
$$

La no alienación (S) se manifiesta como el proceso que inicia la Secretaria, ubicada en S2 (Infe- 
rioridad laboral) y $\overline{\mathrm{S} 1}$ (Inferioridad Social) frente al Funcionario, que participa del polo $\overline{\mathrm{S} 2}$ (Superioridad laboral). El proceso no concluye satisfactoriamente por lo que la no alienación constituye el polo negativo $\overline{(\bar{S})}$ del eje semántico.

\section{LA REFERENCIA SEMANTICA}

Se han venido estableciendo ya algunos alcances semánticos en el nivel sintáctico. Es importante, sin embargo, profundizar en otros que constituyen elementos fundamentales de la significación del supersigno.

\subsection{Relaciones entre personajes}

La iteración $A_{1}$ se puede dividir en dos partes A1.1 en la que participan la Señora Elegante y el Funcionario y A1.2 en la cual aparecen el Funcionario, las Damas Elegantísimas y los Vendedores. El sujeto de $A_{1}$, al igual que los nombres de los personajes que intervienen en la obra, es un prototipo social: La Dama, que tiene dos investimentos semánticos diferentes pero equivalentes. En A1.1 es la Señora Elegante que se impone al empleado por el poder que le da su condición socioeconómica. En A1.2 el sujeto se diluye en 3 personajes (las 3 Damas Elegantísimas) que juntas reiteran la misma idea de superioridad frente a los otros. Coincide esto con la caracterización en bloque que hiciéramos en el punto 3.1, referente a los signos-personaje, de la segmentación cualitativa del supersigno.

En el cuadro No. 6 se establecen las relaciones de estos* personajes con los demás de la iteración, así como el código y matiz en que se ubican dichas relaciones.

CUADRO No. 6

\begin{tabular}{llll}
\hline $\begin{array}{l}\text { Personaje } \\
\text { eje }\end{array}$ & $\begin{array}{l}\text { Relación } \\
\text { con }\end{array}$ & Código & Sistema \\
\hline Dama (s) & $\begin{array}{l}\text { Funciona- } \\
\text { rio }\end{array}$ & $\begin{array}{l}\text { Socioeco- } \\
\text { nómico }\end{array}$ & $\begin{array}{l}\text { Superiori- } \\
\text { dad }\end{array}$ \\
\hline & Vendedores & $\begin{array}{l}\text { Socioeco- } \\
\text { nómico }\end{array}$ & $\begin{array}{l}\text { Superiori- } \\
\text { dad }\end{array}$ \\
\hline
\end{tabular}

Como se ve, el código socioeconómico domina la relación de las damaș con los empleados, quienes aparecen en un nivel inferior a ellas y es por esto que su relación es solamente casual, de servicio hacia ellas.
El sujeto de $A_{2}$ es el Funcionario, cuya participación es cuantitativa y cualitativamente muy destacada. (Veáse cuadro No. 2).

Sus relaciones con los demás personajes de $\mathrm{A}_{2}$ son las siguientes:

CUADRO No. 7

\begin{tabular}{llll}
\hline \hline $\begin{array}{l}\text { Personaje } \\
\text { Eje }\end{array}$ & $\begin{array}{l}\text { Relación } \\
\text { con }\end{array}$ & Código & Sistema \\
\hline $\begin{array}{l}\text { Funcionario } \\
\text { Ojeda }\end{array}$ & Secretaria & Laboral & Superioridad \\
& Gerente & Laboral & Inferioridad \\
& Ministro & Laboral & Inferioridad \\
& & & Servilismo \\
& Vendedores & Laboral & Superioridad \\
\hline \hline
\end{tabular}

En el código laboral oscila el Funcionario entre la superioridad frente a sus subalternos y la inferioridad y servilismo que le impone la relación burocrática con sus superiores. Con la Secretaria mantiene una ambigua relación amorosa en la cual hay matices de superficialidad y erotismo por cuanto sólo se fundamenta en el atractivo sexual.

El sujeto de $A_{3}$ es la Secretaria cuyas relaciones se establecen con el Funcionario bajo un código ético.

CUADRO No. 8

\begin{tabular}{llll}
\hline $\begin{array}{l}\text { Personaje } \\
\text { Eje }\end{array}$ & $\begin{array}{l}\text { Relación con } \\
\text { con }\end{array}$ & Código & Sistema \\
\hline Secretaria & Ojeda & ETICO & $\begin{array}{l}\text { Concientiza- } \\
\text { ción }\end{array}$ \\
\hline
\end{tabular}

El matiz que envuelve la relación es el afán de salir de la ignorancia y la inconsciencia y adquirir la concientización ética acerca del quehacer del Instituto y sus repercusiones sociales.

\subsection{Los enunciados aḍjuntores predicativos}

Para captar el transcurrir de la acción es necesario señalar y analizar estos enunciados en cada una de las iteraciones.

Los cuadros 9,10 y 11 agrupan los personajes y enunciados de cada iteración, los cuales serán objeto de análisis posterior. 
CUADRO No. 9

\begin{tabular}{ll}
\hline$A_{1}$ Personaje & $\begin{array}{l}\text { Enunciados adjuntores pre- } \\
\text { dicativos }\end{array}$
\end{tabular}

Señora Elegante

Entra al Instituto

Conversa con el Funcionario

Presiona para evadir las normas horarias

Apela a su superioridad socioeconómica

Se retira of endida

Funcionario

Recibe a la Señora Elegante

Conversa con la Señora

Mantiene su autoridad frente al deseo de la Señora

Se burla de las formas de acumulación de capital vigentes en la sociedad

Ordena abrir el Departamento de Ventas

Telefonea al Ministro para informarle de los ingresos

\section{Damas Elegantísimas}

Ingresan al recinto

Conversan entre sí y saludan a los empleados

\section{Segunda Dama Elegantísi-} ma

Solicita un pedido especial que aclara al espectador la clave del Instituto
Por su carácter proyectivo, estos enunciados marcan el dinamismo de la acción dramática y el tempo de la misma. Es relativamente fácil, sin embargo, detectar que las predicaciones cuantitativamente mayores se refieren a un estado de cosas y situaciones que se desea hacer evidente al espectador y del cual los actantes participan. Es así como estos enunciados definen estados y no el transcurrir de acciones: conversaciones, instancias, órdenes, respuestas a éstas, saludos, presiones, etc., son algunas de las predicaciones de los personajes del supersigno.

En $A_{1}$ sobresalen las presiones, apelaciones $y$ conversaciones entre los participantes.
CUADRO No. 10

\begin{tabular}{ll}
\hline \hline$A_{2}$ Personajes & $\begin{array}{l}\text { Enunciados adjuntores pre- } \\
\text { dicativos }\end{array}$ \\
\hline Secretaria & Saluda al Director \\
& $\begin{array}{l}\text { Entrega y resume el infor- } \\
\text { me sobre el Instituto }\end{array}$ \\
& $\begin{array}{l}\text { Se niega a mantener con su } \\
\text { aporte al Instituto }\end{array}$ \\
& $\begin{array}{l}\text { Se retira violentamente de } \\
\text { escena }\end{array}$ \\
\hline Funcionario & Saluda a la Secretaria \\
& $\begin{array}{l}\text { Explica por qué se viste } \\
\text { con gabacha }\end{array}$ \\
& $\begin{array}{l}\text { Solicita a la Secretaria su } \\
\text { aporte para el Instituto }\end{array}$ \\
Convierte en orden su soli- \\
citud
\end{tabular}

En $A_{2}$ dominan las órdenes, solicitudes y cumplimiento de ambas partes, ya de los Superiores, ya de los subordinados.

En $\mathrm{A}_{3}$ los enunciados predicativos son instancias, preocupaciones, conversaciones y deseos débi- . les y frustrados.

\subsection{Los enunciados adjuntores cualificativos}

Como su nombre lo indica particularizan las calidades de cada uno de los personajes. Contribuyen, asimismo, a fijar los rasgos definitorios con que se presentan en la obra los prototipos de la sociedad que se intenta satirizar.

Aluden a rasgos físicos y morales en un doble plano: individual y colectivo. 
CUADRO No. 11

$\begin{array}{ll}\mathrm{A}_{3} \text { Personajes } & \begin{array}{l}\text { Enunciados adjuntores pre- } \\ \text { dicativos }\end{array}\end{array}$

\begin{tabular}{ll}
\hline Secretaria & $\begin{array}{l}\text { Ingresa al despacho del } \\
\text { Funcionario }\end{array}$ \\
Saluda y coquetea con el & Funcionario \\
Conversa con el Funcio- \\
nario \\
Entrega y resume el infor- \\
me sobre el Instituto al \\
Funcionario \\
Manifiesta las preocupacio- \\
nes éticas que la asaltan \\
Trata de concientizar al \\
Funcionario \\
Se opone a procrear niños \\
para el Instituto \\
Manifiesta una débil espe- \\
ranza de concientización \\
Deja la escena violenta- \\
mente
\end{tabular}

Funcionario

Conversa con la Secretaria

Galantea con la Secretaria

Explica el origen, funcionamiento y financiación del Instituto

Neutraliza las preocupaciones de la Secretaria describiendo el problema fiscal que se le creará al Estado se oye la voz de la conciencia individual.

Insta a la Secretaria a colaborar con la "materia prima" del Instituto

Convierte su instancia en orden

En el plano individual perfilan al Funcionario, a la Señora Elegante y a la Secretaria. En el plano colectivo dibujan a las Damas Elegantísimas y a los Vendedores que las sirven.

El siguiente cuadro resume las cualificaciones que tiene cada uno.

\subsection{Los Enunciados indicadores}

Hay espaciales, temporales y locales. Concretan los elementos y características del entorno en el que se mueven los personajes. El cuadro No. 13 los presenta en forma esquemática.

Ya habían sido considerados al describir y analizar, en la segmentación cualitativa (Punto 3.2) las realidades físicas, los signos objeto, los signos espacio temporales, etc.; por lo cual volver sobre ellos es reiterado.

\subsection{La tipologıa de personajes}

La relación de superioridad social que se ha venido comprobando en $\mathrm{A}_{1}$ se pone de manifiesto en la línea significativa en que se mueven los personajes de la iteración. La Señora Elegante y las Damas Elegantísimas fungen como las amas frente a los vendedores y servidores que son los criados, es decir, sus subordinados.

En forma gráfica la iteración se resume así: $A_{1}=\operatorname{Ama}(s) \longrightarrow$ Criados

En $\mathrm{A}_{2}$ la relación que se establece, como ya se vió, es de carácter laboral, es decir, entre empleados de diferente jerarquía. El Funcionario Ojeda es el superior, el jefe, frente a los demás, trabajadores. Se puede enunciar así esta iteración: $A_{2}=$ Jefe $\longrightarrow$ Subordinados

La iteración $\mathrm{A}_{3}$ plantea una relación de carácter moral entre la Secretaria y el Superior jerárquico. Oscila entre el ser y el deber, es decir, cuestiona los patrones de conducta vigentes en la sociedad frente a aquellos posibles y verdaderamente humanos.

La Secretaria es quien personifica el intento fallido de cambio, es la portadora de la crítica social. El Funcionario, en cambio, es el criticado. La iteración puede enunciarse así: $A_{3}=$ Críti$\mathrm{ca} \longrightarrow$ Criticado

\section{SIGNIFICACION DE LA OBRA}

El cuadro No. 14 resume la significación total de la obra, en la cual se presentan relaciones socioeconómicas y laborales ubicadas en dos polos: Superioridad/Inferioridad.

Los signos-personaje que representan las clases sociales existentes en Eficaz plan para resolver la desnutrición infantil y de paso los problemas fiscales, ofrecen una doble dicotomía, que los ubica en esas dos líneas de significación: la social y la laboral, dentro de cada una de las cuales ellos mantienen relaciones de igual índole: sociales y laborales. 
CUADRO No. 12

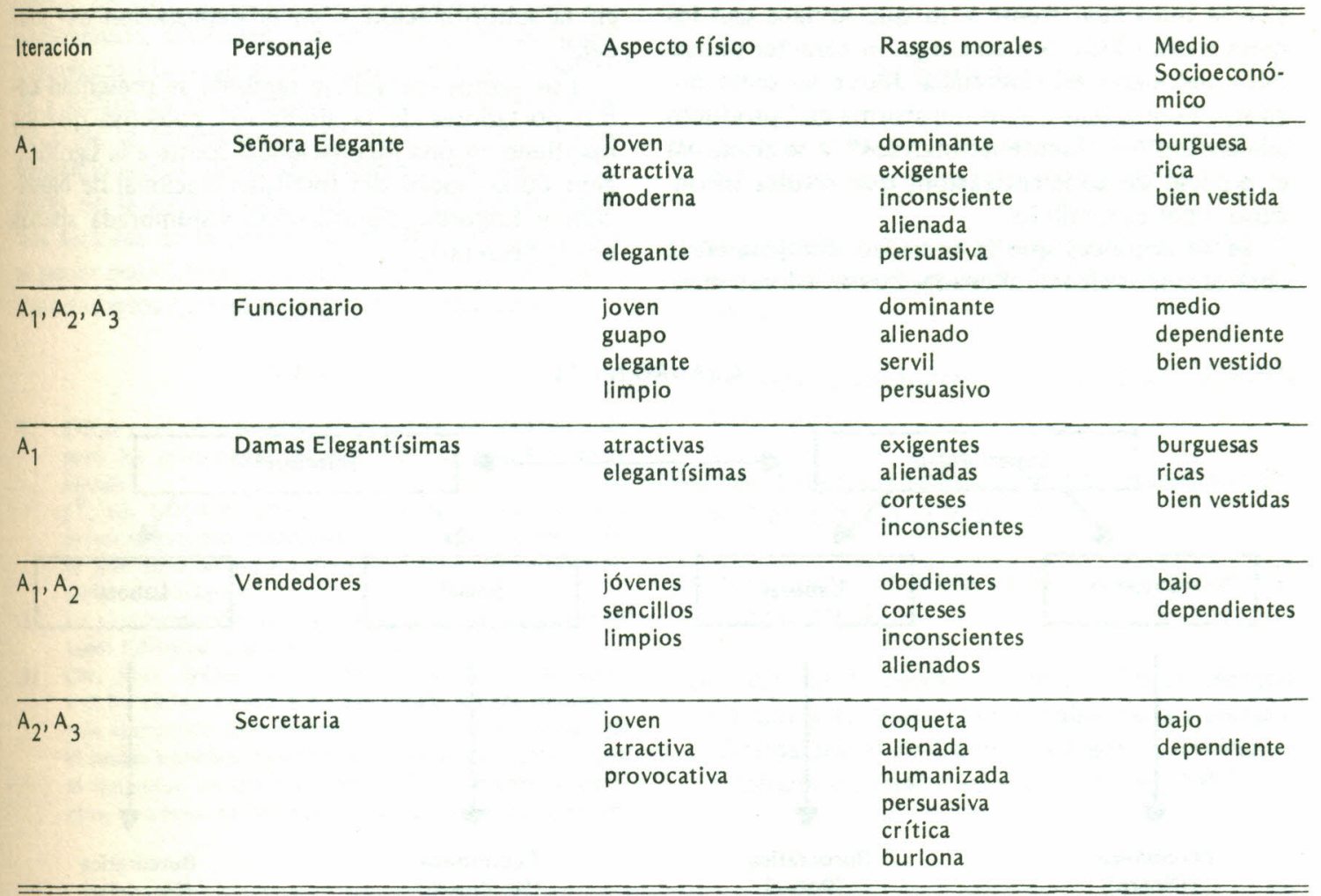

CUADRO No. 13

\begin{tabular}{|c|c|c|c|}
\hline Iteración & $\begin{array}{l}\text { Enunciados } \\
\text { Espaciales }\end{array}$ & $\begin{array}{l}\text { Enunciados } \\
\text { Temporales }\end{array}$ & $\begin{array}{l}\text { Enunciados } \\
\text { Locales }\end{array}$ \\
\hline$A_{1}, A_{2}, A_{3}$ & $\begin{array}{l}\text { Instituto Nacional de } \\
\text { Nutrición y Engorde }\end{array}$ & Jueves de $9: 30$ a 10 horas & . \\
\hline$A_{1}, A_{3}$ & Idem & Idem & $\begin{array}{l}\text { Oficina de Relaciones Públicas } \\
\text { Sala de Ventas }\end{array}$ \\
\hline $\mathrm{A}_{2}$ & Idem & Idem & Oficina de Relaciones Públicas \\
\hline
\end{tabular}

Hay una relación de Superioridad/Inferioridad de carácter social, definida por el poder económico que dan el dinero y la posición.

Hay, asimismo, una relación de Superioridad/Inferioridad de carácter laboral definida por el poder que otorga la burocracia estatal.

El microuniverso que constituye el supersigno patentiza las diferencias producto de la escisión socioeconómica, mediante varios recursos dramáticos. Los más importantes son la gestualidad, la ironía, los matices prosódicos, la kinésica, la proxémi- ca y todos los signos visuales, que se estudiaron en el punto 3.2.

El supersigno, además, se vale de un elemento disyuntor, polisémico, que permite dislocar la significación de la obra: los niños desnutridos. Son estos el motivo generador de la acción presente en las tres iteraciones del complejo. En dos de ellas, $A_{1}$ y $A_{2}$, constituyen la materia con la que se negocia, el producto que los dominadores adquieren de sus subordinados, y el que éstos deben preparar para que esté en su punto. En $\mathrm{A}_{3}$ el elemen- 
to disyuntor permite introducir la crítica, la conciencia individual frente a lo que se hace con los niños desnutridos. Sin embargo, el carácter polisémico del signo en referencia diluye su sema nuclear, "humanidad", y lo transforma en "producto alimenticio" y "fuente de ingresos" y se acalla así el proceso de concientización, que resulta inconcluso y por eso, fallido.

Se ve entonces que la sociedad dibujada en la obra es una sociedad alienada, cuyos valores man- tienen un estado de cosas basado en la desigualdad, en la subordinación y en la explotación del más débil.

Los signos-personaje también se presentan como portadores de la alienación colectiva que los mantiene en una inconsciencia frente a la significación ético-social del Instituto Nacional de Nutrición y Engorde, significación vislumbrada apenas por la Secretaria.

\section{CUADRO No. 14}

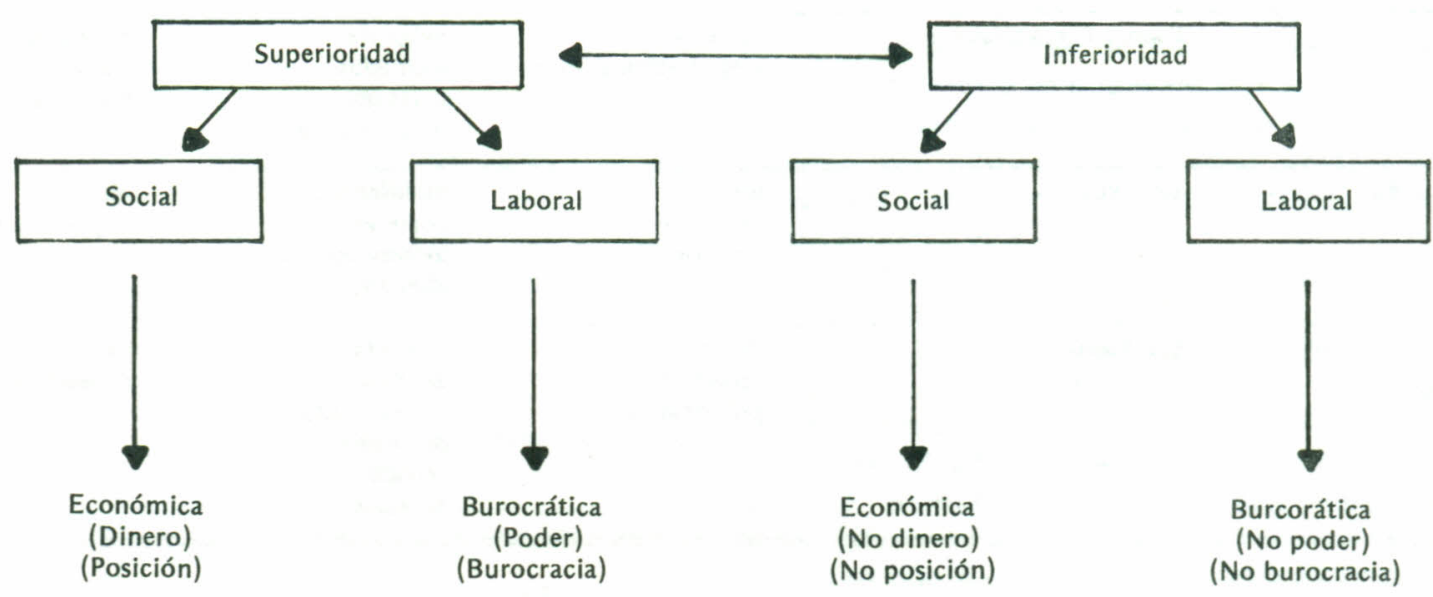

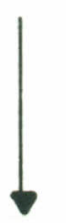

Sra. Elegante Damas Elegantísimas

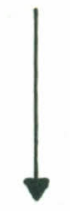

Ministro

Funcionario

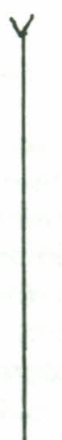

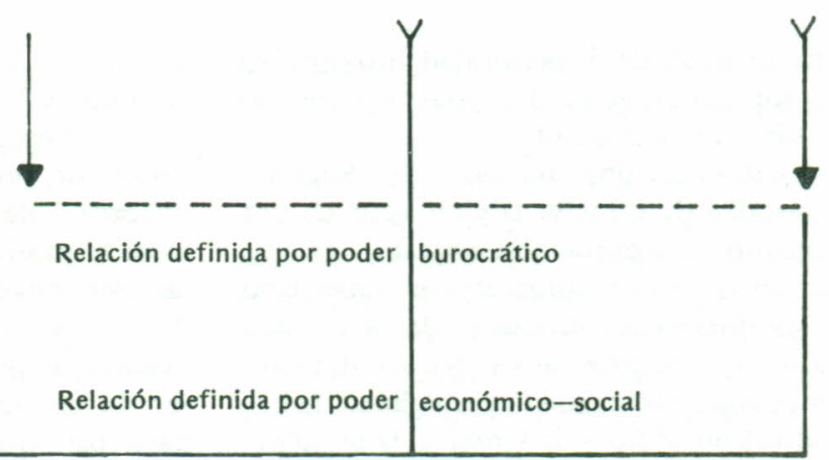

Secretaria Vendedores Servidores 
Finalmente, los signos-personaje son un instrumento de crítica social en la obra pues con sus parlamentos, actitudes y manifestaciones gestuales y kinésicas plantean al espectador una visión satírica y crítica de la sociedad y de la burocracia estatal y de la proliferación de esas instituciones de beneficio social, las cuales actúan como mediatizadoras de la explotación socioeconómica de aquellos sectores de la población no favorecidos ni por el poder económico, ni por el poder político ni por los privilegios que da el nacer en "noble cuna".

\section{NOTAS}

1) Eficaz plan para resolver la desnutrición infantil y de paso los problemas fiscales. En: La Segua y otras piezas.

$5^{\circ}$. ed. EDUCA, 1981. Págs. 67-80. Las citas del presente estudio están tomadas de esta edición, por lo que sólo se hará referencia, entre paréntesis, al número de página.

2) La exterminación de los pobres y otros pienses. San José: Editorial Costa Rica. 1974.

3) Cfr. Max Weber Economía y Sociedad México: F.C.E. 1974. Tomo I p. 242-248. Weber distingue tres elementos que definen la estratificación social: el poder económico entendido como la posición que el individuo ocupa en el mercado de bienes y servicios, el honor social que da la situación personal se- gún su prestigio, y el poder político que da la posibilidad de influir en el comportamiento de otras personas.

\section{BIBLIOGRAFIA}

Bense, Max y Water, Elizabeth. La Semiótica Guía Alfabética. Barcelona: Anagrama, 1975.

Cañas, Alberto. La exterminación de los pobles y otros pienses. San José, Editorial Costa Rica. 1974.

La Segua y otras piezas. $5^{\circ}$. ed. San José. EDUCA. 1981.

Garrido Llovera, Lenín. La imagen teatral. San José: Editorial Costa Rica. 1972.

Kristeva, Julia. El texto de la novela. Barcelona: Lumen, 1974.

Sandoval de Fonseca, Virginia. "En el séptimo círculo o el drama interminable de la violencia. (Drama social de Daniel Gallegos)". Revista de Filología y Lingüística 9 (1): 21-56, 1983. 
